\title{
Influence of the reporter vector backbone on 2-deoxyglucose dependent promoter activation*
}

\author{
Aleksandra Solecka, Aleksandra Wielento, Joanna Jurczak, Weronika Sowińska, \\ Mateusz Wawro and Aneta Kasza ${ }^{\square}$ \\ Department of Cell Biochemistry, Faculty of Biochemistry, Biophysics and Biotechnology, Jagiellonian University, Kraków, Poland
}

\begin{abstract}
Reporter vectors are very often used to investigate mechanisms responsible for regulation of promoter activity. Since their first generation, many new variants were constructed to increase sensitivity and reduce background signal. However, these tools are still imperfect and can generate false results. We have found that depending on the backbone of the reporter vector, pGL3 or pGL2, different results are obtained for a eukaryotic promoter's activation by metabolic changes. These observations were done in the course of investigation of the MMP2 (matrix metalloproteinase-2) promoter regulation in response to inhibition of glycolysis.
\end{abstract}

Key words: reporter vector, gene expression, metalloproteinase 2 , 2-deoxyglucose

Received: 26 April, 2020; revised: 03 June, 2020; accepted: 07 June, 2020; available on-line: 04 September, 2020

⿶e-mail: aneta.kasza@uj.edu.pl

*Presented at the XLVII Winter School of the Faculty of Biochemistry, Biophysics and Biotechnology of the Jagiellonian University "Molecules, Pathways, and Games", February 8-12, 2020, Zakopane, Poland.

Acknowledgments of Financial Support: This work was funded by the Ministry of Science and Higher Education, Poland (MNiSW, Faculty Competition for Research Projects of Young Scientists and PhD Students 2019, N19/MNS/000006).

Abbreviations: 2-DG, 2-deoxyglucose; MMP, metalloproteinase; IER, immediate-early response protein

\section{INTRODUCTION}

Reporter vectors are very often used as tools to investigate gene expression and intracellular reactions related to transcriptional activity in cells. Typically, a reporter gene is controlled by the examined promoter and after transfection of cells, the amount of a reporter protein, its enzymatic activity, or the amount of mRNA of a reporter gene is assessed. The ideal reporter system is characterized by high sensitivity and reproducibility. Importantly, the reporter protein is not endogenously expressed in the recipient cells. This feature enables the use of the reporter protein for monitoring for transfection efficiency, recombination, and studying protein-protein interactions or protein localization in the cells. Besides elements required for all expression vectors, there are a few things to keep in mind when designing reporter vectors used in studies concerning regulation of gene expression. The ideal reporter vector should not contain transcription factor binding sites or regulatory sequences other than those inserted by the researcher. Presence of unknown control elements may lead to nonspecific results, such as increased or decreased synthesis of the reporter protein. The planning part of the experiment, therefore, includes determining factors that need to be controlled to eliminate alternative interpretations of the results. In plasmid-based experiments, typically the transfection efficiency control, as well as negative and positive controls, are of crucial importance (Schenborn \& Groskreutz, 1999; Liu et al., 2009). Elements present in the reporter vector that can affect expression of the reporter gene include signals of polyadenylation and introns. Polyadenylation signals are nucleotide sequences within the 3'UTR that direct binding of the polyadenylation protein complex. The complex contains an endonuclease that cleaves mRNA about 14 to 30 nucleotides downstream of the $\mathrm{A}[\mathrm{A} / \mathrm{U}] \mathrm{UAAA}$ sequence and a polymerase that post-transcriptionally synthesizes a string of about 100 to 200 adenine nucleotides (poly-A tail). Polyadenylation has been shown to increase mRNA stability and translation in mammalian cells (Weill et al., 2012; Neve et al., 2017). Many reporter genes come from bacterial genomes that do not contain introns. For this reason, introns were added to the vectors, making reporter genes more reminiscent of the pattern of exons and introns in mammalian genes. Presence of an intron in the vector sequence has been shown to increase the level of reporter protein synthesis after transfection of the plasmid into mammalian cells (Nott et al., 2003).

Reporter vectors are also used in studies focusing on the influence of metabolism on e regulation of gene expression. Metabolites, such as acetyl-CoA, $\alpha$-ketoglutarate, $\beta$-hydroxybutyrate, butyrate, crotonyl-CoA, $\mathrm{FAD}^{+}$, fumarate, 2-hydroxyglutarate, nicotinamide, nicotinamide' mononucleotide, S-adenosyl-methionine, and succinate are involved in chromatin remodeling (van der Knaap \& Verrijzer, 2016). One of the interesting issues concerning interaction between the pattern of gene expression and cell physiology, is the influence of changes in the glucose metabolism on activation/repression of promoters. Glucose is metabolized via glycolysis to pyruvate, which can be metabolized to $\mathrm{CO}_{2}$ in the tricarboxylic acid (TCA) cycle to generate large amounts of ATP through the process of oxidative phosphorylation (OXPHOS). Pyruvate can be also reduced to organic acids (e.g., lactate) in a process called fermentation (Lunt \& Vander Heiden, 2011). Fast-growing cells primarily rely on glucose fermentation even under oxygen-rich conditions. This phenomenon was described almost 100 years ago by Otto Warburg and is called aerobic glycolysis or the "Warburg effect". Warburg observed that cancer cells rather utilize a high rate of glycolysis followed by lactic acid fermentation in the cytosol, than a low rate of glycolysis followed by OXPHOS in mitochondria, regardless of the oxygen availability. Aerobic glycolysis is not caused by a defect in mitochondrial respiration since respiration is not impaired in most cancer cells (Zu \& Guppy, 2004; Fantin et al., 2006; Moreno-Sánchez 
et al., 2007). It is now well understood that aerobic glycolysis is an adaptation to facilitate uptake and incorporation of nutrients into the biomass needed by fast-growing or proliferating cells (Vander Heiden \& DeBerardinis, 2017). Proliferating cells produce lactate to regenerate $\mathrm{NAD}^{+}$, however, lactate generation may have secondary benefits for tumor cells. The resulting acidification of the extracellular microenvironment promotes survival, growth and invasive behavior of cancer cells via suppression of anticancer T-cell immune response and upregulation of metalloproteinase activity (Fischer et al., 2007; Gillies \& Gatenby, 2007; Gatenby \& Gillies, 2008; López-Lázaro, 2008). Matrix metalloproteinases (MMPs) are enzymes capable of extracellular matrix degradation that are overexpressed during metastasis (Hanahan \& Weinberg, 2011). Under physiological conditions, they play an important role in wound healing, embryonic growth and development, morphogenesis, regulation of the inflammatory response, angiogenesis, and apoptosis. Under pathological conditions, such as rheumatoid arthritis, cardiovascular diseases or tumors, MMPs are overexpressed and activated (Fanjul-Fernández et al., 2010; Kessenbrock, Wang, \& Werb, 2015). Matrix metalloproteinase 2 (MMP-2) belongs to a group of gelatinases. It is constitutively expressed in different cell types and has a broad spectrum of substrates, including gelatin, collagen, elastin, pro-TNF $\alpha$ (tumor necrosis factor type alpha) and TGF $\beta$ (tumor growth factor type ß) (Fanjul-Fernández et al., 2010; Kessenbrock et al., 2015). MMP-2 has been associated with progression of many cancers, including stomach, esophagus, breast, prostate, lungs, bladder, and ovaries cancer. It is particularly important for the invasiveness of gliomas (Ramachandran et al., 2017). Since inhibition of glycolysis is considered as one of the strategies for the treatment of gliomas (Wicks et al., 2015), we decided to study the influence of metabolic changes on expression of MMP-2 in a human glioblastoma cell line.

During our studies, we have discovered that the type of the chosen reporter vector gravely impacts the obtained results. The pattern of promoter activation regulation through cellular metabolism depends on the type of the reporter vector selected for the study.

\section{MATERIALS AND METHODS}

Cell culture. Human astrocytoma U-251 MG cell line was cultured in Dulbecco's Modified Eagle Medium (DMEM) with $4.5 \mathrm{~g} / \mathrm{L}$ D-glucose (BioWest) supplemented with 10\% (v/v) Fetal Bovine Serum (BioWest), at $37^{\circ} \mathrm{C}$ in a humified atmosphere with $5 \% \mathrm{CO}_{2}$.

RNA isolation and reverse transcription. Total RNA was isolated from U-251 MG cells using the modified Chomczynski method (Chomczynski \& Sacchi, 1987). RNA concentration was measured using the NanoDrop ND-1000 spectrophotometer (ThermoFisher Scientific). cDNA was obtained from $1 \mu \mathrm{g}$ of RNA in a reverse transcription reaction using MML-V Reverse Transcriptase (Promega) and $500 \mathrm{ng}$ of oligo(dT) ${ }_{15}$ (Genomed) according to the manufacturer's protocol.

Real-Time PCR. Real-time PCR was performed using SYBRA RT HS-PCR Mix (A\&A Biotechnology) and primers specific to the analyzed transcripts (Genomed):

MMP-2-forward: GTGACGGAAAGATGTGGTG, MMP-2-reverse: GGTGTAGGTGTAAATGGGTG IER3-forward: GGGCTCCGGTCCTGAGATCTTCA, IER3-reverse: GAAGCCTTTTGGCTGGGTTCGGT TBP-forward: GCCAGCTTCGGAGAGTTCTGGGATT TBP-reverse: CGGGCACGAAGTGCAATGGTCTTTA
mRNA level in each sample was analyzed in duplicate, and results were normalized to the reference gene (TBP). The relative level of transcripts was calculated using the $\Delta \Delta \mathrm{C}_{\mathrm{T}}$ method (Pfaffl, 2001).

Gelatin zymography. U-251 MG cells were seeded in 24 -well plates at a density of $5 \times 10^{4}$ cells/well. The next day, the culture medium was exchanged to FBS-depleted medium and 2-deoxy-D-glucose (Cayman Chemical) was added $(12.5 \mathrm{mM})$ for 24 hours. After that, media were collected, cellular debris was removed by centrifugation and samples for SDS-PAGE were prepared by addition of the loading buffer ( $5 \times$ : $312.5 \mathrm{mM}$ Tris $\cdot \mathrm{HCl}, 50 \%$ (v/v) glycerol, 10\% (w/v) SDS, 0.05\% (w/v) bromophenol blue, $\mathrm{pH}=6.8)$ to the prepared media. The electrophoresis was carried out in a Laemmli system (Laemmli, 1970) (5\% stacking gel, $10 \%$ separation gel with $0.1 \%$ (w/v) gelatin). After electrophoresis, the gel was washed and incubated overnight in $2.5 \%(\mathrm{v} / \mathrm{v})$ Triton X-100. The following day, the gel was washed and incubated for 48 hours at $37^{\circ} \mathrm{C}$ with incubation buffer $(10 \mathrm{mM}$ $\mathrm{CaCl}_{2}, 0.15 \mathrm{M} \mathrm{NaCl}, 50 \mathrm{mM}$ TRIS, pH 7.5, 0.01\% (v/v) $\mathrm{NaN}_{3}$ ). Next, the gel was washed with distilled water and stained with a Coomassie Brillant Blue solution $(0.1 \%$ (w/v) Coomassie Brillant Blue R-250, 50\% (v/v) methanol, $10 \%(\mathrm{v} / \mathrm{v})$ acetic acid). The staining solution was removed and the gel was left in the destaining solution $(40 \%$ (v/v) methanol, $10 \%(\mathrm{v} / \mathrm{v})$ acetic acid) until discolored bands were observed. The image was recorded using the Fusion FX5 system (Vilber Lourmat).

Cell migration assay, time-lapse video microscopy. U-251 MG cells were seeded in 24-well plates at the density of $1.5 \times 10^{4}$ cells/well. The following day, the cells were treated with 2-deoxyglucose $(12.5 \mathrm{mM})$ for 24 hours. After that, the cell movement was recorded with a Leica DMI6000B time-lapse system equipped with interference modulation contrast optics, a cooled, digital DFC360FX CCD camera and a chamber maintaining temperature and the $\mathrm{CO}_{2}$ level. Cell trajectories were constructed from the sequence of cell centroid positions recorded at 5-minute intervals for 8 hours. The distance from the starting point directly to the cell's final position (i.e. displacement) were quantified with the Hiro program (Baran et al., 2009).

Cell transfection. U-251 MG cells were seeded in 24well plates at a density of $5 \times 10^{4}$ cells/well. The next day, the cells were transfected with reporter vectors using PEI MAX 40000 (Polysciences) reagent at a reagent to DNA weight ratio of $3: 1$. A total amount of $500 \mathrm{ng}$ DNA per well was used, containing $495 \mathrm{ng}$ of the luciferase encoding plasmid and $5 \mathrm{ng}$ of $\mathrm{pEF} /$ myc-His/ LacZ (control) vector. The medium was exchanged 4 hours post-transfection. The efficiency of transfection was around $60-70 \%$ in all experiments.

Construct generation. The pGL3-MMP-2 construct was prepared by cloning the MMP-2 (NG_008989.1) promoter region from position -3000 to +110 . PCR product was prepared from genomic DNA (gDNA) using Hot Start Q5 Polymerase (NEB). The following primers were used:

forward: TCAGCTAGCTATTGCATGTGCTCACCAACAAGC, reverse: ATAAAGCTTCAGGTCCTGGCAATCCCTTTG.

PCR products were separated by gel electrophoresis, excised, purified (Gel/PCR ME Mini Kit, Syngen), cleaved with NheI and HindIII (NEB) restriction enzymes and purified after enzymatic reaction completion. Thus obtained PCR product was inserted into pGL3-Basic plasmid linearized with NheI and HindIII restriction enzymes and ligated using T4 DNA ligase (ThermoFisher). DEL1 
Table 1. Primer pairs used to obtain deletion variants of the MMP-2 promoter.

\begin{tabular}{|c|c|}
\hline Promoter variant & Primers \\
\hline DEL 1 & $\begin{array}{l}\text { Forward: ATAGCTAGCAAACTGACTCTGGAAAGTCAGAGCAC } \\
\text { Reverse: ATAAAGCTICAGGTCCTGGCAATCCCTITG }\end{array}$ \\
\hline DEL3 & $\begin{array}{l}\text { Forward: ATAGCTAGCGAAGCAACCTGGGACCTTCC } \\
\text { Reverse: ATAAAGCTTCAGGTCCTGGCAATCCCTTTG }\end{array}$ \\
\hline DEL4 & $\begin{array}{l}\text { Forward: ATAGCTAGCGACGAGGTCGTGCACTGAG } \\
\text { Reverse: ATAAAGCTTCAGGTCCTGGCAATCCCTTG }\end{array}$ \\
\hline DEL5 & $\begin{array}{l}\text { Forward: ATAGCTAGCAGTGGAGGAGGGCGAGTAGG } \\
\text { Reverse: ATAAAGCTTCAGGTCCTGGCAATCCCTITG }\end{array}$ \\
\hline DEL6 & $\begin{array}{l}\text { Forward: ATAGCTAGCGACGAGGTCGTGCACTGAG } \\
\text { Reverse: ATAAAGCTTAGGGCAGCCGCCAGATGTAG }\end{array}$ \\
\hline
\end{tabular}

and DEL 3 to DEL6 MMP-2 promoter variants were prepared as described above with primers listed in Table 1. DEL1 was prepared from gDNA, DEL3 to DEL6 from pGL3-MMP-2-DEL1.

pGL3-MMP-2-DEL2 was prepared by cleaving pGL3MMP-2-DEL1 with EcoRI and SacI (NEB) restriction enzymes. Cleavage products were separated by gel electrophoresis, excised and purified, blunted with T4 polymerase (NEB) and ligated with T4 DNA ligase.

A
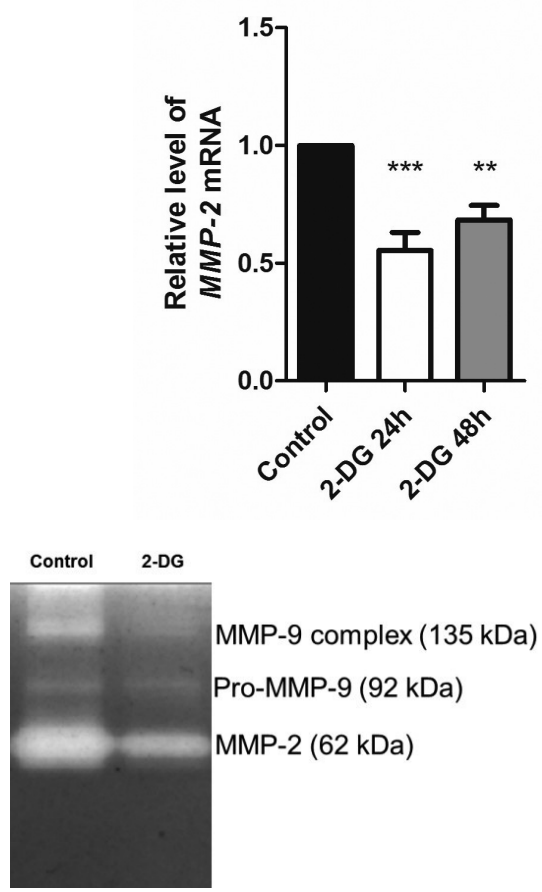

C

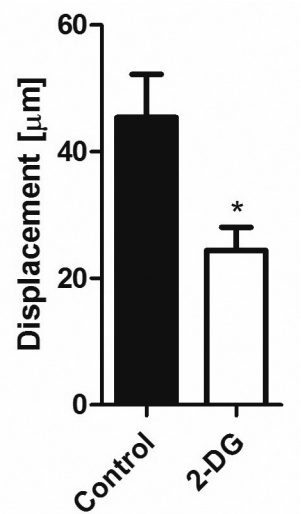

pGL3-MMP-2-DEL7 was generated using Q5 Site-Directed Mutagenesis Kit (NEB) according to the manufacturer's protocol, pGL3-MMP-2 was used as a template and specific primers were as follows:

\section{forward: CCCTTGTTTCCGCTGCAT} reverse: ACCCCACTTGCCTCTCTC.

pGL2-MMP-2 and pGL3-IER3 were obtained by cleavage of pGL3-MMP-2 and pGL2-IER3 (described previously, Kochan et al., 2014) plasmids with KpnI and HindIII (NEB) restriction enzymes. After gel electrophoresis, the products were excised and purified. Then, plasmid backbones were dephosphorylated using rSAP (NEB) according to the manufacturer's protocol. MMP-2 promoter and IER3 promoter were ligated with linearized and dephosphorylated pGL2 and pGL3 plasmids, respectively.

Obtained constructs were verified by restriction analysis and Sanger sequencing (Genomed).

Analysis of luciferase activity. After transfection and 2-DG treatment, the cells were lysed with Passive Lysis Buffer (Promega). The activity of Firefly luciferase was assessed using the Luciferase Assay System (Promega). The activity of $\beta$-galactosidase expressed from the $\mathrm{pEF} / \mathrm{myc}-\mathrm{His} / \mathrm{Lac} Z$ vector was measured using the Beta-Glo Assay System (Promega) and served as control of transfection efficiency.

Sequence analysis. Prediction of transcription factor binding sites was done using the AliBaba2.1 software available online [http://gene-regulation.com/pub/ programs/alibaba2/] and LASAGNA-Search 2.0 (Lee \& Huang, 2013) [https://biogrid-lasagna.engr.uconn.edu/].

Statistics and graphs. Statistical analysis and graphs were done using Graph Pad Prism (v. 5.0, GraphPad Software Inc.). Statistical analysis was performed using the following tests: One-way ANOVA with Tukey's multiple comparison (Fig. 1A) and paired t-test (other figures), $*_{p}<0.05, * * p<0.01, * * * p<0.001$. Schemes of $M M P-2$ pro-

Figure 1. Influence of glycolysis inhibition on expression of MMP-2 (A, B) and cell motility (C).

U-251 MG cells were treated with 2-DG $(12.5 \mathrm{mM})$ for $24 \mathrm{~h}$ or $48 \mathrm{~h}$. A. RNA was isolated from cell lysates, then the mRNA level was assessed using RT-PCR; One-way ANOVA with Tukey's multiple comparison test was used. The plot shows mean results from three independent experiments $(n=3) \pm$ S.D., ${ }^{* *} p<0.01,{ }^{* * *} p<0.001$. B. Culture medium from control and 2-DG treated cells was collected and put into analysis using gelatin zymography. White bands indicate the proteolytic activity of MMPs. C. Cell motility was visualized by time-lapse microscopy and analyzed with the Hiro program (written by W. Czapla). The plot shows mean results from three independent experiments $(n=3) \pm S . D .,{ }^{*} p<0.05$. The paired $t$-test was used. In each experiment, trajectories of 50 cells were analyzed. 
moter variants were prepared using a free diagram software - diagrams.net [www.draw.io].

\section{RESULTS}

Inhibition of glycolysis affects the MMP-2 mRNA level and activity, as well as cell motility

2-deoxy-D-glucose (2-DG) is a glucose analog that acts as an inhibitor of glucose metabolism. It enters cells via GLUT1 transporters and is phosphorylated by hexokinase to 2-DG-P. 2-DG-P cannot be further metabolized and blocks glycolysis (Pelicano et al., 2006). Using 2-DG we examined the influence of the inhibition of glycolysis on the MMP-2 mRNA level in the U251-MG astrocytoma cell line. The results indicate that 2-DG treatment leads to a decrease in the level of MMP-2 transcript (Fig. 1A). To verify the obtained results we examined the activity of the matrix metalloproteinases by zymography (Fig. 1B). This method allows for assessing the proteolytic activity of MMPs in a polyacrylamide gel containing gelatin which is a substrate for MMP-2 and MMP-9. Distinction between these two proteins is possible due to differences in their molecular weights. Changes in metabolism induced by the 2-DG treatment resulted in the decreased activity of both detected MMPs. It is well documented that inhibition of MMP-2 or MMP-9 leads to a decrease in cell migration (Webb et al., 2017). To confirm that the observed changes in the activity and mRNA level of MMP-2 have a physiological effect, we applied a time-lapse video microscopy. The obtained results indicate that cells pretreated with 2-DG show lower ability to displace (Fig. 1C). Taken together, our results suggest that inhibition of glycolysis leads to the decrease in MMP-2 activity, its mRNA level, and reduced mobility of glioblastoma cells.

\section{Analysis of MMP-2 promoter activity after 2-DG treatment}

Changes observed at the mRNA level may result from alterations in the promoter activity or mRNA half-life. We decided to start with the examination of MMP-2 promoter activity following 2-DG treatment. For this purpose, we prepared a series of reporter vectors containing the Firefly luciferase gene under control of different deletion variants of the $M M P-2$ promoter (Fig. 2A). U251-MG cells were transiently transfected with the plasmids generated, and treated with 2-DG. Individual vectors (DEL1 - DEL6) that were used for transfection contain deletions of increasingly larger fragments of the promoter sequence, however, treatment of the cells with 2-DG led to a similar, significant decrease in luciferase activity for each of the used constructs. Based on the obtained results, we selected a potential regulatory region of the $M M P-2$ promoter $(-192$ to +18$)$ responsible for the regulation in response to inhibition of glycolysis. Importantly, this region contains a consensus binding site for the SP1 transcription factor, which is necessary for constitutive expression of $M M P-2$ in human glioblastoma cells (Qin, Sun, \& Benveniste, 1999). To verify the importance of this region in 2-DG-dependent regulation of $M M P-2$ expression, we removed it from the wild type promoter, thus creating the DEL7 construct. However, $M M P-2$ promoter without the investigated fragment $(-192$ to $+18 \mathrm{bp})$ still responded to $2-\mathrm{DG}$ in a similar way as the wild-type promoter (Fig. 2B). Since further shortening of the $M M P-2$ promoter could lead to the re-

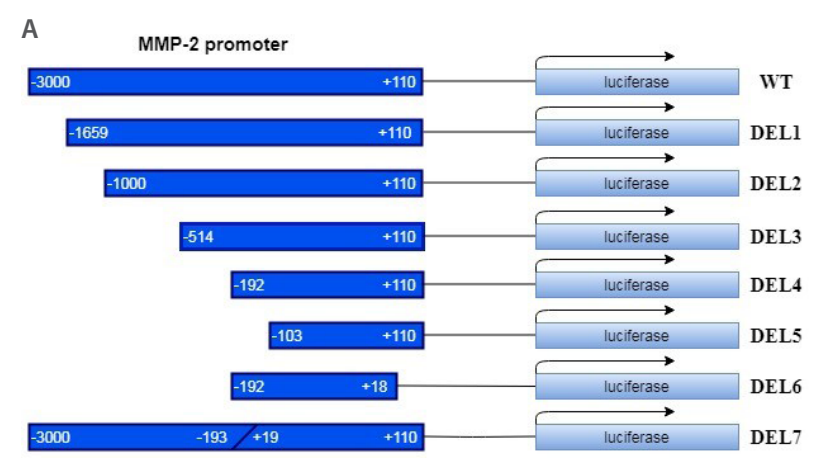

B

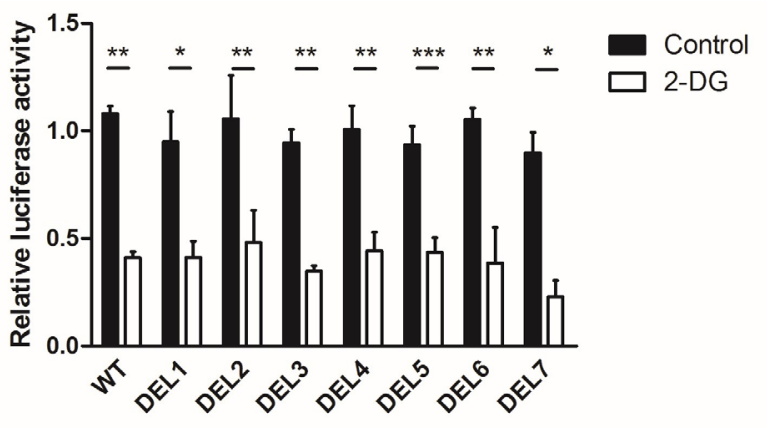

Figure 2. Response of different MMP-2 promoter fragments to the 2-DG treatment in pGL3-based vector series.

A. Scheme of the pGL3-based reporter vector constructs containing the firefly luciferase gene under the control of various fragments of MMP-2. B. Response of the constructs shown in (A) to 2-DG. U251-MG cells were transfected with plasmids containing the reporter gene under MMP-2 promoter control. $24 \mathrm{~h}$ after transfection, the cells were treated with 2-DG $(12.5 \mathrm{mM})$ or left untreated for $24 \mathrm{~h}$. The following day, the cells were lysed and luciferase and $\beta$-galactosidase activity were measured. The plot shows mean results from three independent experiments $(n=3)$ \pm S.D., ${ }^{*} p<0.05,{ }^{* *} p<0.01,{ }^{* * *} p<0.001$. The paired $t$-test was used.

moval of the minimal promoter region, we decided to discontinue this approach.

\section{Analysis of MMP-2 promoter activity in response to glycolysis inhibition using different types of reporter vectors}

Due to the failure to identify regulatory elements in the $M M P-2$ promoter responsible for the observed 2-DG-dependent inhibition, we decided to examine the response to 2-DG treatment of the vector itself. To do this, we re-cloned the wild type $M M P-2$ promoter into another reporter vector - pGL2-Basic, thus obtaining pGL2-MMP-2 vector. In contrast to the results obtained for the pGL3-MMP-2 vector, there were no significant differences in luciferase activity measured in the lysates from cells transfected with the pGL2-MMP-2 vector after 2-DG treatment, in comparison to the control (untreated) cells (Fig. 3A). To further investigate the influence of the vector itself on the 2-DG-dependent promoter activity, we employed two constructs containing the immediate early response 3 (IER3) promoter, namely pGL2-IER3 and pGL3-IER3. Since IER3 is not downregulated by $2-\mathrm{DG}$ (Fig. 3B), both vectors should not respond to 2-DG treatment, similarly to the pGL2-MMP2 and pGL3-MMP2 vectors. However, the luciferase activity in the cells transfected with the pGL3-IER3 construct was significantly decreased after 2-DG treatment, mimicking the pattern of regulation observed for the MMP-2 promoter (pGL3-MMP-2 construct). Simultaneously, we didn't observe such a decrease in luciferase ac- 


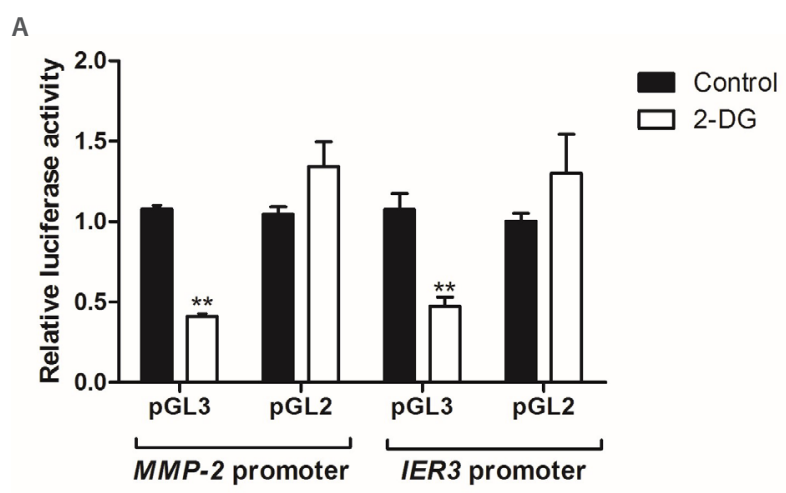

B

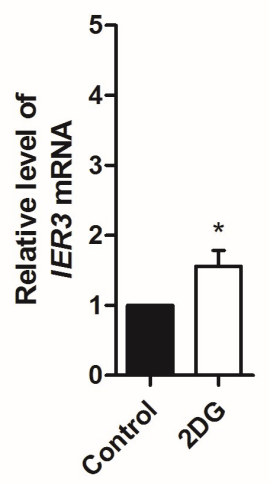

Figure 3A. Influence of the reporter vector backbone on the response of the construct to 2-DG.

U251-MG cells were transfected with plasmids containing the reporter gene under MMP-2 or IER3 promoter control. $24 \mathrm{~h}$ after transfection, the cells were treated with 2-DG $(12.5 \mathrm{mM})$ or left untreated for $24 \mathrm{~h}$. The following day, the cells were lysed and luciferase and $\beta$-galactosidase activity were measured.

Figure 3B. IER3 mRNA level after inhibition of glycolysis.

U251-MG cells were stimulated with IL-1 $1(10 \mathrm{ng} / \mathrm{ml})$ for $2 \mathrm{~h}$ to induce IER3 expression and then treated with 2-DG $(12.5 \mathrm{mM})$ or left untreated (control). RNA was isolated from cell lysates and then the mRNA level was assessed using RT-PCR. The plots show mean results from three independent experiments $(n=3) \pm S . D$., ${ }^{*} p<0.05$, ${ }^{* *} p<0.01$. The paired $t$-test was used

tivity in lysates from cells transfected with pGL2-IER3 (Fig. 3A). The obtained results clearly indicate that the originally observed down-regulation of the $M M P-2$ promoter activity in response to inhibition of glycolysis by 2-DG was an effect of the response of the regulatory elements present in the originally used pGL3-Basic vector backbone rather than the elements present in the $M M P-2$ promoter itself.

\section{DISCUSSION}

Our study reveals the importance of the type of reporter vector used in research focused on investigation of the effect of metabolic changes on promoter activation. We have analyzed the outcome of the use of the pGL3 and pGL2 vectors for such studies. The pGL3 vector is one of Promega's next generation expression vectors. In comparison to pGL2, its backbone has been altered to increase the luciferase expression (Promega Corporation, 2008a, 2008b). Four major modifications of the vector backbone were introduced: 1) the early poly(A) SV40 signal was replaced with a late signal to increase transcription termination efficiency and polyadenylation of luciferase transcripts (Carswell \& Alwine, 1989); 2) synthetic poly(A) and a transcription pause site were placed above MCS to limit non-specific transcription that can be initiated within the vector backbone (Enriquez-Harris et al., 1991; Levitt et al., 1989); 3) the small T antigen intron has been removed to prevent a decreased expression of the reporter gene due to cryptic RNA splicing (Evans \& Scarpulla, 1989; Huang \& Gorman, 1990); 4) optimal Kozak consensus sequence was inserted to increase the efficiency of luciferase gene translation initiation (Kozak, 1989). In addition, the pGL3 vector carries a modified gene encoding Fireflyluciferase (luc +$)$. The main modifications that distinguish the luc + gene from the native luciferase gene include: 1) removal of the $\mathrm{C}$ terminal tripeptide to eliminate peroxisome targeting; 2) improving the use of codons for expression in plant and animal cells; 3) removal of two potential N-glycosylation sites; 4) DNA sequence changes to remove internal restriction sites and eliminate consensus sequences recognized by regulatory proteins (Promega Corporation, 2008b; Sherf \& Wood, 1994). Bioinformatics prediction of transcription binding sites using AliBaba2.1 software showed that the pGL3-Basic plasmid contains 370 recognition sites for transcription factors, whereas there are 446 such sites in the pGL2-Basic sequence.

Our work is part of a series of studies on the effect of metabolism on gene expression regulation. In 2013, Chang et al. showed that aerobic glycolysis is engaged in posttranscriptional regulation of specific cellular functions. $\mathrm{T}$ cells fully supported by oxidative phosphorylation have a severe defect in IFN- $\gamma$ (interferon $\gamma$ ) production. This effect is due to a block in translation (Chang et al., 2013). Independently, in the same year, Tannahill et al. described the influence of glycolysis on expression of interleukin $1 \beta$ (IL-1 $\beta$ ) in mouse macrophages. Inhibition of glycolysis results in suppression of LPS (lipopolysaccharide) induced transcription of the IL-1 $\beta$ gene. This effect is caused by changes in the stability of the transcription factor HIF-1 $\alpha$ (hypoxia-inducible factor $1 \alpha$ ) which participates in stimulation of IL-1 $\beta$ expression. Expression of TNF in investigated cells was not regulated by glycolysis (Tannahill et al., 2013).

In this study, we made an attempt to identify the mechanisms underlying downregulation of $M M P-2$ expression after glycolysis inhibition. Originally, our results suggested that the observed regulation of MMP-2 by 2-DG occurs at the promoter level. However, despite preparation of a series of promoter deletion variants, we were not able to identify a sequence that could play a significant role in response to the 2-deoxyglucose treatment. All constructs, containing wild type and deletion variants of the $M M P-2$ promoter, and generated using the pGL3 vector as a backbone were downregulated in response to the $2-\mathrm{DG}$ treatment. To verify whether the pGL3-based system is a proper experimental setup, we prepared a construct containing the wild-type $M M P-2$ promoter using a different reporter vector backbone, the pGL2-Basic vector. Surprisingly, the previously observed 2-DG induced down-regulation was no longer visible in cells transfected with the pGL2-based vector. Moreover, we detected a similar pattern of vectorbackbone dependent regulation by 2-DG for the IER3 promoter, while IER3 expression is not down-regulated by this compound. Thus, the originally observed 2-DGdependent regulation of $M M P-2$ expression at the promoter level didn't rely on the sequences present in the investigated promoter but was due to the presence of regulatory elements in the pGL3 plasmid that was used.

Considering the reduction in recognition sites for transcription factors in pGL3-Basic backbone in comparison 
to the pGL2-Basic backbone (370 versus 446, respectively), one would expect a lower influence of the plasmid sequence on the investigated promoter activation. However, our data suggest that the use of the pGL3 vector leads to a false decrease in activation of the investigated promoters in response to 2-DG. This study raises the problem of choosing the right model for experiments based on reporter vectors.

The authors declare no conflict of interest.

\section{REFERENCES}

\section{REFERENCES}

Baran B, Bechyne I, Siedlar M, Szpak K, Mytar B, Sroka J, łaczna E, Madeja Z, Zembala M, Czyz J (2009) Blood monocytes stimulate migration of human pancreatic carcinoma cells in vitro: The role of tumour necrosis factor - alpha. Eur. J. Cell Biol. 88: 743-752. https://doi.org/10.1016/j.ejcb.2009.08.002

Carswell S, Alwine JC (1989) Efficiency of utilization of the simian virus 40 late polyadenylation site: effects of upstream sequences. Mol. Cell. Biol. 9: 4248-4258. https://doi.org/10.1128/mcb.9.10.4248

Chang CH, Curtis JD, Maggi LB, Faubert B, Villarino AV, O'Sullivan D, Huang SCC, Van Der Windt GJW, Blagih J, Qiu J, Weber JD, Pearce EJ, Jones RG, Pearce EL (2013) Posttranscriptional control of $\mathrm{T}$ cell effector function by aerobic glycolysis. Cell 153: 12391251. https://doi.org/10.1016/j.cell.2013.05.016

Chomczynski P, Sacchi N (1987) Single-step method of RNA isolation by acid guanidinium thiocyanate-phenol-chloroform extraction. Anal. Biochem. 162: 156-159. https://doi.org/10.1016/00032697(87)90021-2

Enriquez-Harris P, Levitt N, Briggs D, Proudfoot NJ (1991) A pause site for RNA polymerase II is associated with termination of transcription. EMBO J. 10: 1833-1842. https://doi. org/10.1002/j.1460-2075.1991.tb07709.x

Evans MJ, Scarpulla RC (1989) Introns in the 3'-untranslated region can inhibit chimeric CAT and $\beta$-galactosidase gene expression. Gene 84: 135-142. https://doi.org/10.1016/0378-1119(89)90147-9

Fanjul-Fernández M, Folgueras AR, Cabrera S, López-Otín C (2010) Matrix metalloproteinases: Evolution, gene regulation and functional analysis in mouse models. Biochim. Biophys. Acta - Mol. Cell Res. 1803: 3-19. https://doi.org/10.1016/i.bbamcr.2009.07.004

Fantin VR, St-Pierre J, Leder P (2006) Attenuation of LDH-A expression uncovers a link between glycolysis, mitochondrial physiology, and tumor maintenance. Cancer Cell 9: 425-434. [published correction appears in Cancer Cell (2006) 10: 172] https://doi.org/10.1016/j. ccr.2006.07.011

Fischer K, Hoffmann P, Voelkl S, Meidenbauer N, Ammer J, Edinger M, Gottfried E, Schwarz S, Rothe G, Hoves S, Renner K, Timischl B, Mackensen A, Kunz-Schughart L, Andreesen R, Krause SW, Kreutz M (2007) Inhibitory effect of tumor cell-derived lactic acid on human T cells. Blood 109: 3812-3819. https://doi.org/10.1182/ blood-2006-07-035972

Gatenby RA, Gillies RJ (2008) A microenvironmental model of carcinogenesis. Nat. Rev. Cancer 8: 56-61. https://doi.org/10.1038/ nrc2255

Gillies RJ, Gatenby RA (2007) Hypoxia and adaptive landscapes in the evolution of carcinogenesis. Cancer Metastasis Rev. 26: 311-317. https://doi.org/10.1007/s10555-007-9065-z

Hanahan D, Weinberg RA (2011) Hallmarks of cancer: The next generation. Cell 144: 646-674. https://doi.org/10.1016/j.cell.2011.02.013

Vander Heiden MG, DeBerardinis RJ (2017) Understanding the intersections between metabolism and cancer biology. Cell 168: 657-669. https://doi.org/10.1016/j.cell.2016.12.039

Huang MT, Gorman CM (1990) The simian virus 40 small-t intron, present in many common expression vectors, leads to aberrant splicing. Mol. Cell. Biol. 10: 1805-1810. https://doi.org/10.1128/ mcb.10.4.1805

Kessenbrock K, Wang CY, Werb Z (2015) Matrix metalloproteinases in stem cell regulation and cancer. Matrix Biol. 44-46: 184-190. https://doi.org/10.1016/j.matbio.2015.01.022

van der Knaap JA, Verrijzer CP (2016) Undercover: Gene control by metabolites and metabolic enzymes. Genes Dev. 30: 2345-2369. https://doi.org/10.1101/gad.289140.116

Kochan J, Wawro M, Kolka A, Maczuga P, Kasza A (2014) Transcription factor Elk-1 participates in the interleukin-1ß-dependent regulation of expression of immediate early response gene 3 (IER3). Cytokine 70: 120-125. https://doi.org/10.1016/j.cyto.2014.06.021
Kozak M (1989) The scanning model for translation: An update. J. Cell Biol. 108: 229-241. https://doi.org/10.1083/jcb.108.2.229

Laemmli UK (1970) Cleavage of structural proteins during the assembly of the head of bacteriophage T4. Nature 227: 680-685. https:// doi.org/10.1038/227680a0

Lee C, Huang CH (2013) LASAGNA-search: An integrated web tool for transcription factor binding site search and visualization. Biotechniques 54: 141-153. https://doi.org/10.2144/000113999

Levitt N, Briggs D, Gil A, Proudfoot NJ (1989) Definition of an efficient synthetic poly(A) site. Genes Dev. 3: 1019-1025. https://doi. org $/ 10.1101 / \operatorname{gad} .3 .7 .1019$

Liu AMF, New DC, Lo RKH, Wong YH (2009) Reporter gene assays. Methods Mol. Biol. 486: 109-123. https://doi.org/10.1007/9781-60327-545-3_8

López-Lázaro M (2008) The warburg effect: why and how do cancer cells activate glycolysis in the presence of oxygen? Anticancer. Agents Med. Chem. 8: 305-312. https://doi. org/10.2174/187152008783961932

Lunt SY, Vander Heiden MG (2011) Aerobic glycolysis: meeting the metabolic requirements of cell proliferation. Annu. Rev. Cell Dev. Biol 27: 441-464. https://doi.org/10.1146/annurev-cellbio-092910-154237

Moreno-Sánchez R, Rodríguez-Enríquez S, Marín-Hernández A, Saavedra E (2007) Energy metabolism in tumor cells. FEBS J. 274: 13931418. https://doi.org/10.1111/j.1742-4658.2007.05686.x

Neve J, Patel R, Wang Z, Louey A, Furger AM (2017) Cleavage and polyadenylation: Ending the message expands gene regulation. $R N A$ Biol. 14: 865-890. https://doi.org/10.1080/15476286.2017.1306171

Nott A, Meislin SH, Moore MJ (2003) A quantitative analysis of intron effects on mammalian gene expression. RNA 9: 607-617. https:// doi.org/10.1261/rna.5250403

Pelicano H, Martin DS, Xu RH, Huang P (2006) Glycolysis inhibition for anticancer treatment. Oncogene 25: 4633-4646. https://doi. org/10.1038/sj.onc.1209597

Pfaffl MW (2001) A new mathematical model for relative quantification in real-time RT-PCR. Nucleic Acids Res. 29: https://doi.org/10.1093/ nar/29.9.e45

Promega Corporation (2008a) pGL2 Luciferase Reporter Vectors Technical Manual. 1-30.

Promega Corporation (2008b) pGL3 Luciferase Reporter Vectors Technical Manual. 1-30.

Qin H, Sun Y, Benveniste EN (1999) The transcription factors Sp1, $\mathrm{Sp} 3$, and AP-2 are required for constitutive matrix metalloproteinase-2 gene expression in astroglioma cells. J. Biol. Chem. 274: $29130-$ 29137. https://doi.org/10.1074/jbc.274.41.29130

Ramachandran RK, Sørensen MD, Aaberg-Jessen C, Hermansen SK, Kristensen BW (2017) Expression and prognostic impact of matrix metalloproteinase-2 (MMP-2) in astrocytomas. PLoS One 12: e0172234. https://doi.org/10.1371/journal.pone.0172234

Schenborn E, Groskreutz D (1999) Reporter gene vectors and assays. Appl. Biochem. Biotechnol. - Part B Mol. Biotechnol. 13: 29-44. https:// doi.org/10.1385/MB:13:1:29

Sherf BA, Wood KV (1994) Firefly Luciferase Engineered for Improved Genetic Reporting. [WWW document]. Promega Notes Mag. $14-21$.

Tannahill GM, Curtis AM, Adamik J, Palsson-Mcdermott EM, McGettrick AF, Goel G, Frezza C, Bernard NJ, Kelly B, Foley NH, Zheng L, Gardet A, Tong Z, Jany SS, Corr SC, Haneklaus M, Caffrey BE, Pierce K, Walmsley S, Beasley FC et al. (2013) Succinate is an inflammatory signal that induces IL-1 $\beta$ through HIF- $1 \alpha$. Nature 496: 238-242. https://doi.org/10.1038/nature11986

Webb AH, Gao BT, Goldsmith ZK, Irvine AS, Saleh N, Lee RP, Lendermon JB, Bheemreddy R, Zhang Q, Brennan RC, Johnson D, Steinle JJ, Wilson MW, Morales-Tirado VM (2017) Inhibition of MMP-2 and MMP-9 decreases cellular migration, and angiogenesis in in vitro models of retinoblastoma. BMC Cancer 17: https://doi. org/10.1186/s12885-017-3418-y

Weill L, Belloc E, Bava FA, Méndez R (2012) Translational control by changes in poly(A) tail length: Recycling mRNAs. Nat. Struct. Mol. Biol. 19: 577-585. https://doi.org/10.1038/nsmb.2311

Wicks RT, Azadi J, Mangraviti A, Zhang I, Hwang L, Joshi A, Bow H, Hutt-Cabezas M, Martin KL, Rudek MA, Zhao M, Brem H, Tyler BM (2015) Local delivery of cancer-cell glycolytic inhibitors in high-grade glioma. Neuro. Oncol. 17: 70-80. https://doi.org/10.1093/ neuonc/nou143

Zu XL, Guppy M (2004) Cancer metabolism: Facts, fantasy, and fiction. Biochem. Biophys. Res. Commun. 313: 459-465. https://doi. org/10.1016/j.bbrc.2003.11.136 